\title{
METABOLISM OF L-THYROXINE BY HUMAN TISSUE SLICES *
}

\author{
By EDWIN C. ALBRIGHT AND FRANK C. LARSON \\ (From the Department of Medicine, University of Wisconsin Medical School, Madison, Wis.)
}

(Submitted for publication May 11, 1959; accepted July 6, 1959)

The deiodination of L-thyroxine to triiodothyronine has been observed in vitro using surviving rat kidney slices $(1,2)$. Surveys of other rat tissues have not shown consistent deiodination of thyroxine, but occasional appearances of trace quantities of triiodothyronine in surviving heart slices and diaphragm (3) have led to the belief that other tissues in the rat convert thyroxine to triiodothyronine at a slower rate than kidney.

Relevance of these observations to human physiology might be questioned on the ground that conversion of L-thyroxine to triiodothyronine by extrathyroidal tissues is peculiar to the rat. In this connection, a previous report (4) that deiodination of L-thyroxine occurred in an athyreotic human has been retracted (5). It therefore seemed pertinent to examine the L-thyroxine deiodinating enzyme system of extrathyroidal tissues of the human. The purpose of this paper is to report such experiments employing tissue slices of human kidney, liver, skeletal muscle and heart.

\section{METHODS}

Materials and preparation. Samples of human kidney, liver, heart and skeletal muscle were obtained at operation. Adequate quantities of normal kidney tissue were available from nephrectomy in patients with renal carcinoma. Wedge biopsies of liver were carried out during laparotomy. Intercostal or rectus muscle samples were obtained during thoracotomy or laparotomy, and limited quantities of left auricular appendage were available during mitral commissurotomy.

The isolated tissue was immediately placed in chilled Krebs-Ringer phosphate solution. Slices (300 to $500 \mathrm{mg}$. wet weight) were prepared using a Stadie-Riggs apparatus.

Reaction procedure. The reaction mixture (final volume $3 \mathrm{ml}$.) consisted of Krebs-Ringer phosphate solution $(\mathrm{pH} 7.4)$ to which $0.01 \mu \mathrm{g}$. of $\mathrm{I}^{131}$-labeled L-thyrox-

* This work was supported in part by the Research Committee of the Graduate School from funds supplied by the Wisconsin Alumni Research Foundation, and by a grant from Smith, Kline \& French Laboratories. Presented June 4, 1959 at the Annual Meeting of the Endocrine Society, Atlantic City, N. J. ine ${ }^{1}$ was added. Incubation was carried out at $37^{\circ} \mathrm{C}$. for six hours. Tissue slices boiled for 10 minutes were used as a control.

Extraction and scparation of products. At the end of the period of incubation the slices were removed, rinsed and homogenized in $2 \mathrm{ml}$. of water. The homogenates were extracted with 10 volumes of 3 per cent concentrated ammonium hydroxide in butanol. The extracts were concentrated to a small volume, marker thyronine compounds were added and the sample dried on Whatman No. $3 \mathrm{~mm}$. paper for chromatography. Chromatograms were run in descent for 24 hours using a tertiary amyl alcohol-2 $\mathrm{N}$ ammonium hydroxide solvent system. The radioactive compounds were located on the strips with a continuously recording automatic scanner. The position of the marker compounds was determined by color development with 4-amino-antipyrine reagent. ${ }^{2}$ With the solvent system used, the $R_{f}$ values of the thyronine compounds in simple solution are: thyroxine, 0.20 ; tetraiodothyroacetic acid, 0.30 ; triiodothyronine, 0.40 and triiodothyroacetic acid, 0.56 . The presence of extraneous material derived from butanol extraction of the tissues has a tendency to proportionally lower the $R_{f}$ values, as seen in Figure 1. For this reason, marker compounds are always added.

A portion of the thyronine compounds is lost during the extraction procedure. Approximately 60 per cent of the radioactivity added as thyroxine appears on the chromatogram. For this reason, the quantity of triiodothyronine derived from thyroxine can only be estimated by comparing the relative quantities of thyroxine and triiodothyronine on the chromatogram. This is done by measuring the area under the radioactivity curves. Recognizing that thyroxine is randomly labeled in the $3^{\prime}$ and $5^{\prime}$ positions and that the incidence of double labeling is negligible, it follows that the labeled triiodothyronine represents only one-half of the labeled thyroxine present on the chromatogram. This may be expressed as a per

1 Obtained from Abbott Laboratories.

2 The application of the 4-amino-antipyrine reagent (6) to the detection of thyronine compounds and their acetic acid analogues was suggested by Dr. Leon Saunders, Smith, Kline and French Laboratories. The chromatogram is first sprayed with a 2 per cent solution of 4-aminoantipyrine in 2 per cent sodium carbonate and then with a 2 per cent solution of potassium ferricyanide. Tetraiodinated compounds give a lavender, triiodinated a red and diiodinated an orange color. The method is somewhat more sensitive than the diazo method previously used in this laboratory. 


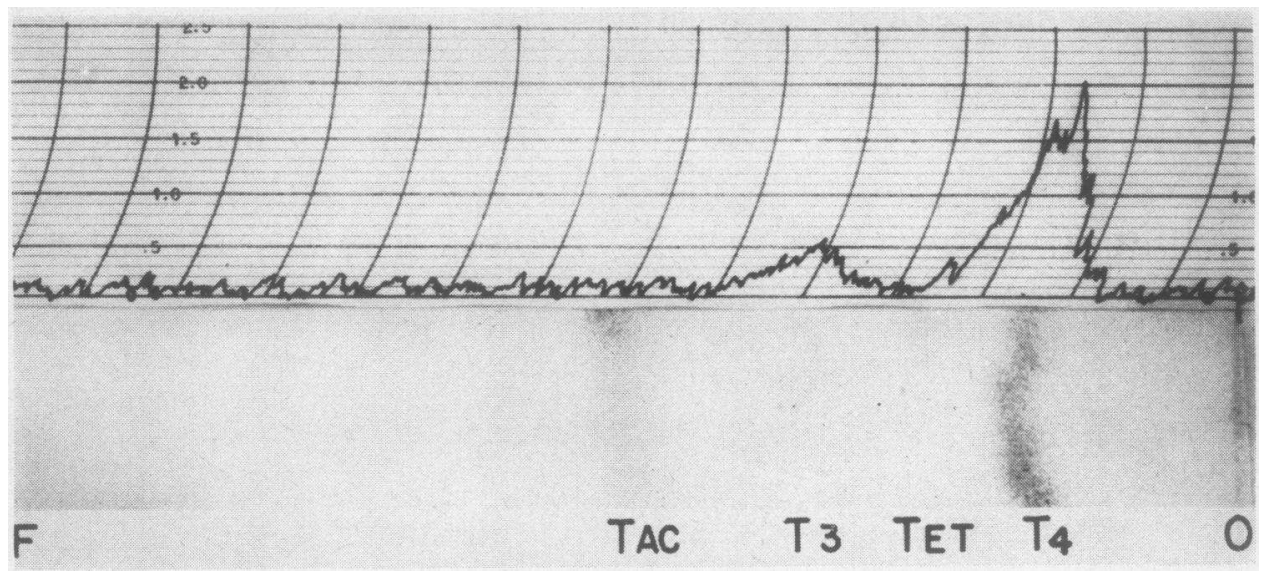

Fig. 1. Radiochromatogram From Human Kidney Slice Experiment Showing DeiodinaTION OF I ${ }^{181}$-LABELED L-THYROXINE TO TRIODOTHYRONINE

Note separation of triiodothyronine from tetrac. $\mathrm{O}=$ origin of chromatogram, $\mathrm{F}=$ solvent front. Position of marker compounds: $T_{4}$, thyroxine; TET, tetraiodothyroacetic acid: $T_{:}$, triiodothyronine; TAC, triiodothyroacetic acid.

cent as follows :

per cent triiodothyronine derived from thyroxine $=$ $\frac{2 \times \text { triiodothyronine radioactivity }}{2 \times \text { triiodothyronine radioactivity }+} \times 100$.

\section{RESULTS}

With kidney slices radioactivity regularly appeared at the position of triiodothyronine. The extent of conversion of thyroxine to triiodothyronine ranged from 11 to 38 per cent (mean 22 per cent) (Table I) in 10 consecutive experiments. Iodide liberated by the deiodinating system does not appear on the chromatogram due to its partial loss into the reaction mixture during incubation and to the unfavorable partition ratio (10:1, water to butanol) during ammoniacal butanol extraction

TABLE I

The extent of conversion of $I^{131}$-labeled L-thyroxine to triiodothyronine by human kidney slices

\begin{tabular}{cc}
\hline $\begin{array}{c}\text { Experiment } \\
\text { No. }\end{array}$ & Per cent \\
\hline 1 & 16 \\
2 & 11 \\
3 & 29 \\
4 & 15 \\
5 & 18 \\
6 & 16 \\
7 & 38 \\
8 & 34 \\
9 & 26 \\
10 & 20 \\
\hline
\end{tabular}

of the residue. I representative experiment is shown in Figure 2, demonstrating the appearance of triiodothyronine in the viable tissue and its absence in the boiled control. A separate experiment is shown in Figure 1 in which, in addition to triiodothyronine, tetraiodothyroacetic acid and triiodothyroacetic acid were added as marker compounds. Separation of tetraiodothyroacetic acid from triiodothyronine is demonstrated. The only labeled reaction product observed is triiodothyronine. ${ }^{3}$

Tissues other than kidney showed little or no deiodination as illustrated in Figure 3 . In an occasional experiment with heart slices, a small peak appeared at the triiodothyronine position but this finding was sufficient neither in quantity nor consistency to establish the reaction in this tissue.

\section{DISCLSSION}

Two physiological origins of triiodothyronine have been proposed: 1 ) the coupling of diiodotyrosine and monoiodotyrosine in the thyroid and

3 The labeled reaction product from thyroxine substrate is considered not to be tetraiodothyroacetic acid for several reasons: the separation of triiodothyronine and tetraiodothyroacetic acid with the solvent system used is very satisfactory (Figure 1), the color of the compounds with 4-amino-antipyrine is distinguishable (Footnote 2 ), and with slice preparations tetraiodothyroacetic acid has not been encountered, whereas it has been observed using mitochondrial enzyme systems. 
its secretion as such from the gland, and 2) the monodeiodination of thyroxine in extrathyroidal tissues.

There is general agreement that triiodothyronine is formed in the thyroid, and there is evidence that circulating triiodothyronine is derived from this source rather than from deiodination of thyroxine in peripheral tissues. The thyroidal vein of animals was found to contain more triiodothyronine than is present in the general body circulation (7), and patients with no functioning thyroid tissue did not have significant plasma levels of labeled triiodothyronine following the administration of labeled thyroxine (5). Since cells have a greater affinity for triiodothyronine than for thyroxine, it would be surprising if triiodothyronine formed intracellularly were released into the circulation. The low concentration of triiodothyronine in plasma relative to thyroxine does not necessarily reflect the quantitative output from the gland. Labeled triiodothyronine injected intravenously rapidly leaves this compartment and appears in tissues while thyroxine, preferentially protein-bound, is maintained at higher levels in the intravascular compartment.

Production of triiodothyronine by the gland does not exclude its alternative origin from thyroxine in target tissues. It is quite possible that both mechanisms are operative. The proposal of Gross and Pitt-Rivers (8) that the conversion of thyroxine to triiodothyronine is an essential preliminary step in the "activation" of thyroid hormone is supported by several observations: 1) the relatively longer latent period between administration of thyroxine and appearance of maximal metabolic effects than is observed with triiodothyronine; 2) recovery of a labeled compound subsequently identified as triiodothyronine from plasma and tissues following injection of labeled thyroxine in thyroidectomized mice (9) or propylthiouraciltreated rats $(10) ; 3)$ demonstration of deiodination of thyroxine to triiodothyronine in vitro by surviving rat kidney slices $(1) ; 4)$ the direct relationship between the rate of the deiodination re-

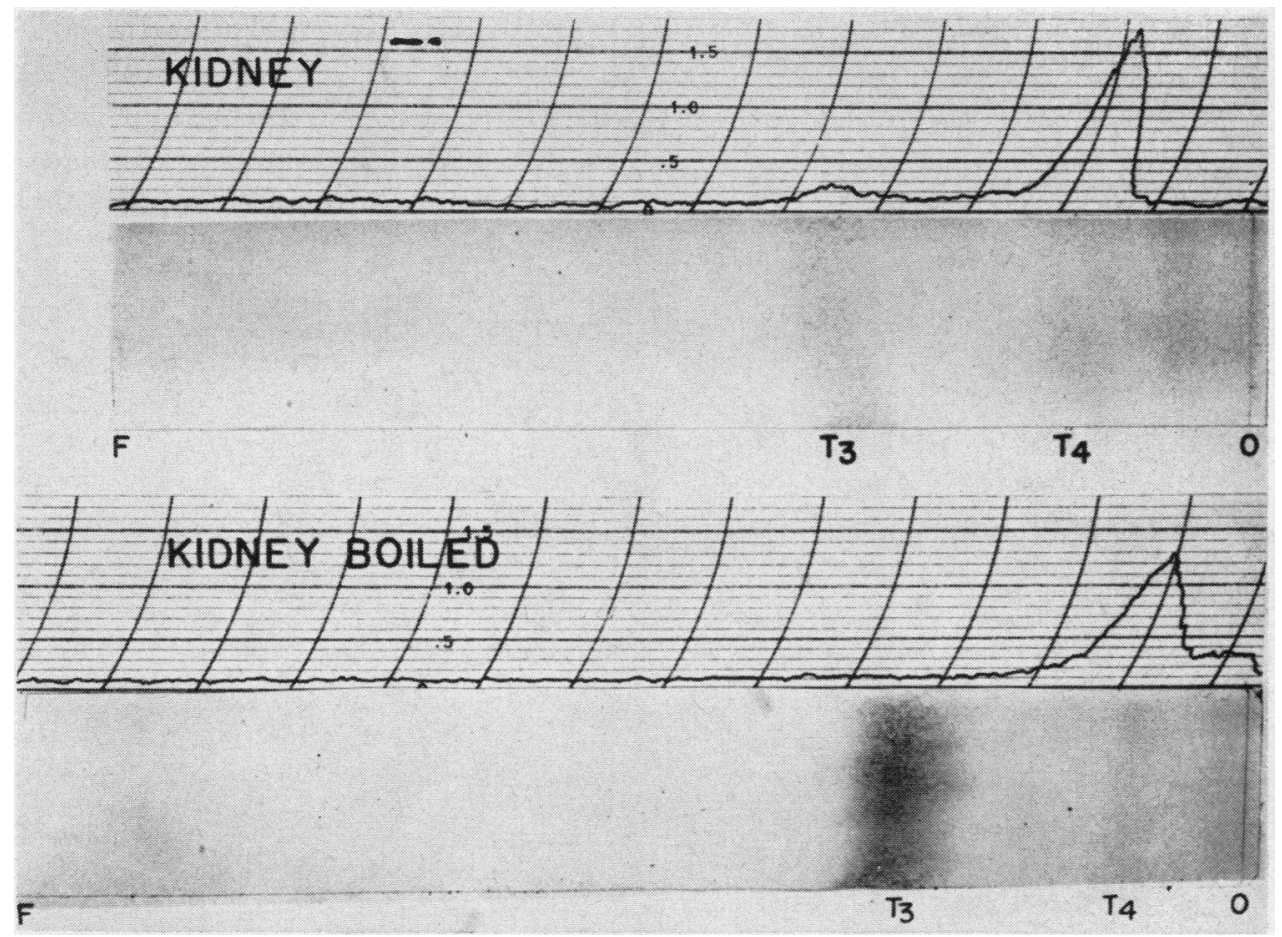

Fig. 2. Radiochromatogram From Human Kidney Slice Experiment Showing Deiodination of I ${ }^{31}$-Labeled L-Thyroxine to Triodothyronine With Surviving Tissue and the Absence of Labeled Triodoth yronine With Tissue Inactivated by Boiling

$\mathrm{O}=$ origin of chromatogram, $\mathrm{F}=$ solvent front. Position of marker compounds: $\mathrm{T}_{4}$, thyroxine; $T_{3}$, triiodothyronine. 

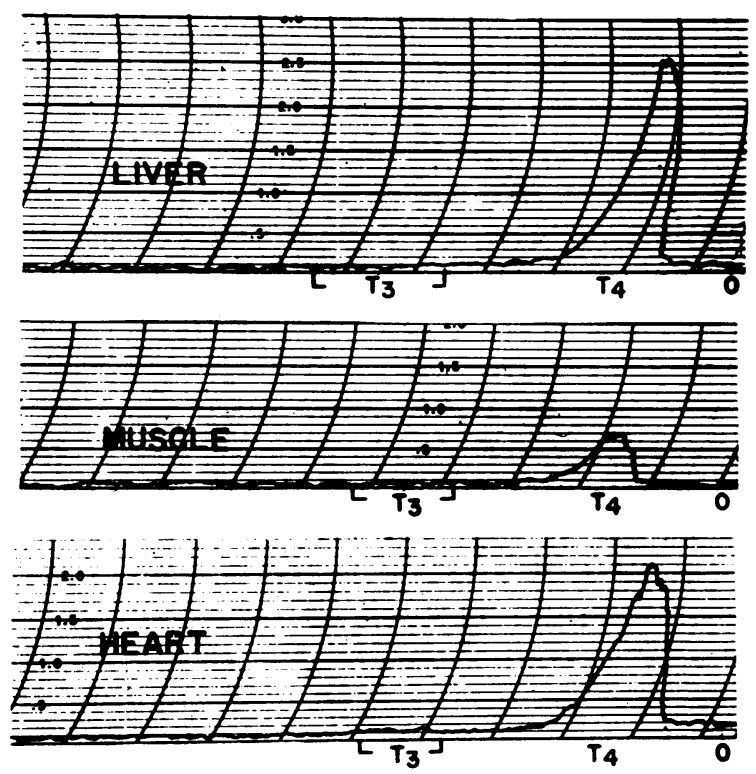

Fig. 3. Radioactivity Records From Chromatograms of Human Liver, Skeletal Muscle and Heart Experiments With I ${ }^{131}$-Labeled L-Thyroxine as Substrate

Note the absence of triiodothyronine peak with liver and muscle. $\mathrm{O}=$ origin of chromatogram. Solvent front not shown. Position of marker compounds: $T_{4}$, thyroxine: $T_{s}$, triiodothyronine.

action and the level of thyroid activity (11); and $5)$ the failure of D-thyroxine, which has little or no metabolic activity, to undergo deiodination in these in vitro systems (12).

The results obtained in this study are essentially the same as observed previously in rat tissues. Kidney regularly and most actively deiodinates Lthyroxine to form triiodothyronine while other tissues show little or no deiodination. Occasional appearance of trace quantities of triiodothyronine has been observed with rat heart and diaphragm, and a similar finding has been noted in experiments with human heart (Figure 3 ). This suggests the possibility that tissues other than kidney may convert thyroxine to triiodothyronine at a much slower rate. The reason for the greater activity of this enzyme system in the kidney is unknown. It is unlikely that it represents a degradative reaction related to the excretory function of this organ since triiodothyronine is more active than thyroxine. More plausible is the possibility that it is related to the high metabolic rate of this tissue. The $\mathrm{QO}_{2}$ of kidney is reported to be three to four times as great as liver, hve to six times as great as skeletal muscle and seven to eight times as great as heart (13). In situ activation of thyroxine by conversion to triiodothyronine at different rates would permit extrathyroidal tissues to control the level of hormone stimulation locally.

Technical considerations offer difficulty in demonstrating triiodothyronine formation by tissues having a less active deiodinating enzyme system than the kidney. Based on the daily consumption of $200 \mu \mathrm{g}$. of thyroxine by a $70 \mathrm{Kg}$. man, and assuming that all of it is converted to triiodothyronine by extrathyroidal tissues and that all tissues carry out the transformation at the same rate, approximately $0.001 \mu \mathrm{g}$. of thyroxine would be deiodinated to triiodothyronine per $G$. of tissue per six hours by any tissue. In the present experiments the weight of tissue used was in the range of 300 to $500 \mathrm{mg}$. We would expect, therefore, that with the above assumptions only 0.0003 to $0.0005 \mu \mathrm{g}$. of thyroxine would be converted to triiodothyronine. Since $0.01 \mu \mathrm{g}$. of thyroxine was added to each flask, the average yield would be 3 to 5 per cent of the substrate used, a quantity difficult to detect even by isotopic methods. It is evident, therefore, that only in tissue in which deiodination of thyroxine to triiodothyronine occurs at a rate considerably higher than average can triiodothyronine be observed under these experimental conditions.

\section{SUMMARY}

The enzymatic deiodination of $\mathrm{I}^{131}$-labeled $\mathrm{L}$ thyroxine to triiodothyronine by human extrathyroidal tissues has been examined using surviving slices prepared from kidney, heart, liver and skeletal muscle. With kidney, the appearance of labeled triiodothyronine was regularly observed. The extent of conversion of thyroxine to triiodothyronine by this tissue ranged from 11 to 38 per cent in six hours. With heart, trace amounts of triiodothyronine were noted occasionally, but in quantity insufficient to definitely establish the reaction in this tissue. Triiodothyronine formation was not observed in liver and muscle. It is suggested that the greater activity of the thyroxine-deiodinating enzyme in kidney is related to the high metabolic rate of this tissue. 


\section{REFERENCES}

1. Albright, E. C., Larson, F. C., and Tust, R. H. In vitro conversion of thyroxine to triiodothyronine by kidney slices. Proc. Soc. exp. Biol. (N. Y.) 1954, 86, 137.

2. Cruchaud, S., Vannotti, A., Mahaim, C., and Deckelmann, J. The in vitro effect of methylthiouracil and estradiol monophosphate on the conversion of thyroxine to triiodothyronine by kidney slices. Lancet 1955, 296, 906.

3. Albright, E. C., and Larson, F. C. Unpublished observations.

4. Pitt-Rivers, R., Stanbury, J. B., and Rapp, B. Conversion of thyroxine to $3: 5: 3^{\prime}$-triiodothyronine in vivo. J. clin. Endocr. 1955, 15, 616.

5. Lassiter, W. E., and Stanbury, J. B. The in vivo conversion of thyroxine to $3: 5: 3^{\prime}$-triiodothyronine. J. clin. Endocr. 1958, 18, 903.

6. Emerson, E. The condensation of aminoantipyrine II. A new color test for phenolic compounds. J. org. Chem. 1943, 8, 417.
7. Taurog, A., Wheat, J. D., and Chaikoff, I. L. Nature of the $\mathrm{I}^{181}$ compounds appearing in the thyroid vein after injection of iodide $-\mathrm{I}^{181}$. Endocrinology 1956, 58, 121.

8. Gross, J., and Pitt-Rivers, R. Physiological activity of 3:5:3'-L-triiodothyronine. Lancet 1952, 262, 593.

9. Gross, J., and Leblond, C. P. Metabolites of thyroxine. Proc. Soc. exp. Biol. (N. Y.) 1951, 76, 686.

10. Kalant, H., Lee, R., and Sellers, E. A. Metabolic fate of radioactive thyroid hormones in normal and propylthiouracil-treated rats. Endocrinology 1955, 56, 127.

11. Larson, F. C., Tomita, K., and Albright, E. C. The deiodination of thyroxine to triiodothyronine by kidney slices of rats with varying thyroid function. Endocrinology 1955, 57, 338.

12. Larson, F. C., Tomita, K., and Albright, E. C. In vitro metabolism of $\mathrm{D}$-thyroxine. Endocrinology 1959, 65, 336.

13. Barker, S. B. Metabolic actions of thyroxine derivatives and analogs. Endocrinology 1956, 59, 548. 